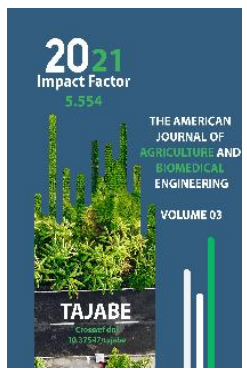

Journal Website: http://theamericanjour nals.com/index.php/taj abe

Copyright: Original content from this work may be used under the terms of the creative commons attributes 4.0 licence.

\section{The Effect Of Organic And Mineral Fertilizers On The Growth And Development Of Cotton}

\author{
Ismailov Uzaqbay Emberdenovich \\ Doctor Of Agricultural Sciences, Professor, Nukus Branch Of Tashkent State Agrarian \\ University Nukus, Uzbekistan \\ Ismailova Aqsingul Uzaqbayevna \\ Assistant, Nukus Branch Of Tashkent State Agrarian University Nukus, Uzbekistan \\ Satbaeva Elvira \\ Master, Nukus Branch Of Tashkent State Agrarian University Nukus, Uzbekistan \\ Maqulbaev Qudaybergan Xo'jambergenovich \\ Assistant, Nukus Branch Of Tashkent State Agrarian University Nukus, Uzbekistan
}

\title{
ABSTRACT
}

Experiments were conducted on studying the effects of organic and mineral fertilizers on the growth, development and productivity of cotton in saline soils of the Republic of Karakalpakstan. In practice, the annual norm of mineral fertilizer (N250 P175 K125 kg / ha) was reduced by 25\% (N185 P130 K90 kg / ha) and an additional 10 and $20 \mathrm{t} / \mathrm{ha}$ of organic fertilizer was used. As a result of the experiment, when organic fertilizer was used at the amount of $20 \mathrm{t} / \mathrm{ha}$, and mineral fertilizer was used at the amount of $\mathrm{N} 185 \mathrm{P} 130 \mathrm{~K} 90 \mathrm{~kg} / \mathrm{ha}$ the growth, development and productivity of cotton were improved and mineral fertilizer was economized by $25 \%$.

\section{KEYWORDS}

Grapes, wine, sort, fertileness, productivity indicators, bush load, harvested branches, buds, developing rod.

\section{INTRODUCTION}

In order to get higher yields from cotton, we need to use new agro-technologies, introduce crop-rotation, and improve the reclamation of arable lands.

One of the most important factors influencing the growth, development and productivity of cotton is using organic fertilizers in improving soil productivity and cotton yield. Using organic fertilizers improves the agro physical, agrochemical and microbiological properties of the soil. 
Method of the experiment. Field method.

Object of the experiment. Saline soils, cotton, organic and mineral fertilizers.

Results of the research and analyzing them. In practice, influence of fertilizers was studied in the following variants: variant 1, N250 P175 K125 kg / ha, variant 2, N250 P175 K125 kg / ha + $10 \mathrm{t}$ of organic fertilizer, variant 3, N185 P130 $\mathrm{K} 90 \mathrm{~kg} / \mathrm{ha}+10 \mathrm{t} / \mathrm{ha}$ of organic fertilizer, variant $4 \mathrm{~N} 250 \mathrm{P} 175 \mathrm{~K} 125 \mathrm{~kg} / \mathrm{ha}+20$ t organic fertilizer, variant $5 \mathrm{~N} 185 \mathrm{P} 130 \mathrm{~K} 90 \mathrm{~kg} / \mathrm{ha}+20 \mathrm{t}$ / ha organic fertilizer.

We conducted a survey on September 1 to determine the effect of organic and mineral fertilizers, and celadon green on the growth and development of cotton. In the survey, the height of the main stem was taken into account, as well as the number of fruitful branches and buds.

The growth and development of the plant is primarily affected by soil fertility, in addition to this the agrophysical and agrochemical properties of the soil, providing with nutrient, water and air regimes, the stem number and the beneficial temperature influences on it.

In field experiment, we studied 1 variant (N250 P175 K125 kg / ha) with a complete amount of mineral fertilizer comparing with the variant in which organic fertilizer in different amount and additional $25 \%$ of shortened NPK (N180 $\mathrm{P} 130 \mathrm{~K} 90 \mathrm{~kg} / \mathrm{ha}$ ) were used together.

The average height of a main stem of cotton was $77.0-92.2 \mathrm{~cm}$ according to the variants, the number of fruitful branches were 13.1-15.1 and the number of buds was 9.9-11.8.
As can be seen in Table (1), the lower value was observed in variants 1 and 3 . In this case, only mineral fertilizers were used in variant 1 , in variant 3 , the amount of mineral fertilizer was reduced by $25 \%$ and an additional 10 tons of organic fertilizer was provided, so the reduced $25 \%$ of mineral fertilizer could not be replaced by the amount of 10 tons of organic fertilizer. When in variant 4 the total amount of mineral fertilizer and $20 \mathrm{t}$ of organic fertilizer, and in variant 5 mineral fertilizer was reduced by $25 \%$ and in addition 20 tons of organic fertilizer were used, all indicators were higher, or comparing to the variant 1 , the height of the plant was higher by $15,2 \mathrm{~cm}$, the number of fruitful branches and buds was more by 2 pieces, and when mineral fertilizer was reduced by $25 \%$ and in addition 20 tons of organic fertilizer was used in variant 4, all indicators were higher than variant 1.

The reduction of the amount of mineral fertilizer in the diet of cotton by $25 \%$ and the provision of 20 tons of organic fertilizer to replace it, created a favorable environment for the growth and development of cotton. In practice, in addition to organic fertilizer, mineral fertilizer was used in combination. At the same time, the amount of mineral fertilizer is saved by $25 \%$, it is replaced by using organic fertilizer, the amount of mineral salts in the soil is reduced, the agrophysical, agrochemical and microbiological properties of the soil are improved. This method is considered to be beneficial for all aspects of both environmental and economic development. It is important in improving saline, unproductive soils. 
Table - 1

The growth and development of cotton. $1^{\text {st }}$ September

\begin{tabular}{|c|c|c|c|}
\hline Variants & $\begin{array}{c}\text { The height of the main } \\
\text { stem, cm }\end{array}$ & $\begin{array}{c}\text { Number of fruitful } \\
\text { branches, piece }\end{array}$ & Number of buds, piece \\
\hline 1 & 77,0 & 13,1 & 9,9 \\
\hline 2 & 87,5 & 14,4 & 10,6 \\
\hline 3 & 76,3 & 12,0 & 10,3 \\
\hline 4 & 92,2 & 15,1 & 11,8 \\
\hline 5 & 88,0 & 14,0 & 11,0 \\
\hline
\end{tabular}

In order to be high-yielding, all its vital factors must be present at the level required by the plant, including nutrients, water, heat and light. If these factors are not provided to the extent required by the plant, then the last indication is that the fertility of the plant will be low, depending on how low the factors are. If one of these factors is the deficient, and the other factors are enough, the productivity will be on the level of the deficient factor.
In practice, we have determined the effect of the amount of organic fertilizer in the nutrition of the plant. Cotton weight in a bud and number of buds on a plant influences on cotton productivity.

In variants of picking, the weight of cotton in a bud was 4.2-4.6 g.

Table - 2

Cotton weight in a bud, $g$

\begin{tabular}{|c|c|c|c|c|c|c|}
\hline \multirow[t]{2}{*}{ Variants } & \multicolumn{4}{|c|}{ Picking } & \multirow[t]{2}{*}{ Average } & \multirow{2}{*}{$\begin{array}{c}\text { Difference, } \\
\pm\end{array}$} \\
\hline & 1 & 2 & 3 & 4 & & \\
\hline 1 & 5,1 & 4,3 & 4,1 & 3,3 & 4,2 & 00 \\
\hline 2 & 5,5 & 4,4 & 4,3 & 3,7 & 4,5 & $+0,3$ \\
\hline 3 & 5,0 & 4,5 & 3,9 & 3,4 & 4,2 & 00 \\
\hline 4 & 5,5 & 5,2 & 4,7 & 3,7 & 4,8 & $+0,6$ \\
\hline 5 & 5,6 & 4,7 & 4,4 & 3,7 & 4,6 & $+0,4$ \\
\hline
\end{tabular}


The weight of cotton in one bud was $4.2 \mathrm{~g}$ in variant 1 fed with the full amount of mineral fertilizers (N250 P175 K125 kg / ha). It was $4.5 \mathrm{~g}$ when $10 \mathrm{t}$ of organic fertilizer is added to the total amount of mineral fertilizer (var. 2). However, when the amount of mineral fertilizer was reduced by $25 \%$ and an additional 10 tons of organic fertilizer was given (var. 3), the weight of cotton in one bud was fully equal to the indicator in varinat 1 , which was fed with the full amount of mineral fertilizers.

The weight of cotton in one bud was 4.8 and $4.6 \mathrm{~g}$ when fed with the full amount of mineral fertilizers (var. 4) and the amount of mineral fertilizer was reduced by $25 \%$ and an additional 20 tons of organic fertilizer was given (var. 5), and it was more by 0.6-0.4 g. comparing to variant 1 , in which full amount of mineral fertilizers was used.

In the case of the variants studied, the weight of cotton in one bud showed that it was higher in both 4 and 5 variants, and that this food regime was more advantageous than the other food regimes.
It has been found that while different food regimes influence on the weight of cotton in a bud and the number of buds in a plant, so does they influence on cotton productivity.

Cotton yields were average 26.3-31.1 quintals. The total amount of mineral fertilizer was 27.1 quintals in variant 1 , which was used alone. When the amount of mineral fertilizer was reduced by $25 \%$ and an additional 10 tons of organic fertilizer was used in variant 3 the yield was 27.1 quintals, which is 0.6 quintals more than in variant 1.

When the organic waste was increased to 10 tons, the yield was 30.7-31.1 quintals. This provided 3.6-4.0 quintals of crop yield more than variant 1 . When 20 tons of organic fertilizer is used in combination with $25 \%$ reduced amount of mineral fertilizer (var. 5), yield was 30.7 quintals. In other words, by reducing the amount of mineral fertilizers by $25 \%$, the yield was 30.7 quintals when 20 tons of organic fertilizers were used together, and the yield was more by 3.6 quintals compared to variant 1 , which was used in full.

Table - 3

Cotton productivity connected to food regime, $q /$ ha

\begin{tabular}{|c|c|c|c|c|c|}
\hline \multirow{2}{*}{ Variants } & \multicolumn{3}{|c|}{ Rotation } & \multirow{2}{*}{ Average } & Difference, \\
\cline { 2 - 4 } & I & II & III & \pm \\
\hline 1 & 28,3 & 26,7 & 26,3 & 27,1 & 00 \\
\hline 2 & 29,3 & 27,5 & 28,1 & 28,3 & $+1,2$ \\
\hline 3 & 27,0 & 29,0 & 27,1 & 27,7 & $+0,6$ \\
\hline 4 & 30,5 & 32,0 & 30,8 & 31,1 & $+4,0$ \\
\hline 5 & 31,0 & 30,5 & 30,5 & 30,7 & $+3,6$ \\
\hline
\end{tabular}


$\mathrm{md}=0,61$ ц.га; HCP $=2,25 \%$

\section{CONCLUSION}

This diet saves $25 \%$ of mineral fertilizer, so much mineral salts do not fall into the soil, and its ecological condition improves. The agrophysical, agrochemical and microbiological condition of the soil is improved through the use of organic fertilizer.

This means that this food regime is both economically and environmentally beneficial.

In the case of saline soils, to receive high cotton yield, to increase the productivity of the soil and to save $25 \%$ of mineral fertilizers, it is necessary to use $\mathrm{N} 185 \mathrm{P} 130 \mathrm{~K} 90 \mathrm{~kg} / \mathrm{ha}$ mineral fertilizers and in addition to this $20 \mathrm{t} /$ ha of organic fertilizers.

\section{REFERENCES}

1. Ismailov U.E. Scientific basis of improving soil productivity. Nukus. - Knowledge. 2004. 185 p.

2. Bauatdinov T., Tajibaev S., Bauatdinov S. The technology of receiving mineral fertilizer on the basis of phosphorus and celadon green in Karakalpakstan. Scientific works of Nukus branch TSAU. Nukus. 2005.

3. Ismailov U.E., Seytnazarov S. Agricultural problems and ways for solving them. Nukus. 2010. Knowledge. 28 p.

4. Tursunxojaev Z.S. Scientific basis of crop rotation. Tashkent. Fan. 1972. 180 p. 